Original Article

\title{
Physical Performance, Balance, Mobility, and Muscle Strength Decline at Different Rates in Elderly People
}

\author{
Márcia Mariko Nakano ${ }^{1)}$, Thais Satie Otonari ${ }^{1)}$, Kelly Sayuri Takara ${ }^{1)^{*} \text {, }}$ \\ Carolina M (armo ${ }^{1)}$, Clarice Tanaka ${ }^{1)}$ \\ 1) Department of Physical Therapy, Communication Science and Disorders, Occupational Therapy, \\ Faculty of Medicine, University of São Paulo: Dr. Enéias de Carvalho Aguiar, 155, Cerqueira César, \\ CEP 05403-000, Brazil
}

\begin{abstract}
Purpose] The aim of this study was to verify the decline in functionality of elderly people. [Subjects and Methods] The study subjects comprised 152 individuals (96 women; 56 men) divided into 3 groups: G1 (60 to 69 years, $n=53$ ); G2 (70 to 79 years, $n=65$ ); and G3 (80 years or older, $n=34)$. Physical performance, balance, mobility, and muscle strength were assessed using Short Physical Performance Battery (SPPB), Berg Balance Scale (BERG), Timed Up and Go (TUG) test, and leg press test, respectively. Comparison among age-stratified groups (G1, G2 and G3) and between genders were examined using analysis of variance with Tukey's test as a post hoc test or the Kruskal-Wallis test with Bonferroni correction. [Results] SPPB and BERG scores decreased significantly in comparison between G1 and G3, and between G2 and G3 in women. TUG and leg press scores decreased significantly in comparison between G1 and G3 and between G2 and G3. [Conclusion] People in their 60s and 70s have similar functional characteristics (physical performance, balance, mobility and muscle strength for both genders), and functionality starts to decline when people are in their $80 \mathrm{~s}$.

Key words: Postural balance, Muscle strength, Mobility limitation
\end{abstract}

(This article was submitted Sep. 13, 2013, and was accepted Nov. 10, 2013)

\section{INTRODUCTION}

Changes in balance, mobility, and muscle strength are associated with aging and interfere with performance of activities of daily living and functional capacity. Functional activities such as walking remain critical in the elderly population because of loss of mobility and muscle strength, which may increase the risk of falls ${ }^{1-3)}$.

Muscle strength starts to decrease early in the life span, with losses of about $12-15 \%$ per decade after 50 years of age $^{4)}$, and this figure might be as high as $50 \%$ in people above 80 years of age ${ }^{3)}$. The importance of balance, mobility, and muscle strength to maintenance of functional capacity within the complex scenario of aging is already known ${ }^{5}$. The older population may present with functional impairment earlier than 70 years of age because of the decline in different physical aspects. The decrease in temporal nature of many intricate physical aspects during the aging process needs to be identified as soon as possible to avoid important functional losses.

Knowledge concerning the functional profiles of age-

*Corresponding author. Kelly Sayuri Takara (E-mail: kelly. stak@gmail.com)

(C2014 The Society of Physical Therapy Science. Published by IPEC Inc. This is an open-access article distributed under the terms of the Creative Commons Attribution Non-Commercial No Derivatives (by-ncnd) License $<$ http://creativecommons.org/licenses/by-nc-nd/3.0/>. stratified groups of elderly people would provide a better approach to the maintenance of functionality and the prevention of falls and functional dependency through public health programs.

The aim of this study was to verify the functionality decline by age group. We intended to achieve this by comparing physical performance, balance, mobility, and muscle strength in age-stratified groups of elderly people.

\section{SUBJECTS AND METHODS}

The study included 152 (56 men, 96 women) participants ranging from 60 to 96 years of age. All of the participants signed an approved consent form. The inclusion criteria were subjects who were 60 years of age or older; had a minimum score of 18 on the mini-mental state examination (MMSE), indicating normal cognitive status ${ }^{6)}$ and had the capability to walk with or without any support accessories such as a cane or walker, excluding wheelchairs. Subjects with cognitive, visual, or verbal communication issues were excluded. The participants were recruited at the Physiotherapy and Geriatrics Outpatient Facility, Hospital das Clínicas da Faculdade de Medicina da USP and were divided into 3 age-stratified groups: G1 (60 to 69 years), G2 (70 to 79 years), and G3 (80 years or older). The same trained professional collected data from the participants for the clinical and sociodemographic characterization and performed all the assessments for each participant in the same sequence 
as bellow, with no time interval between them, taking from 25 to 45 minutes per participant. This cross-sectional, exploratory and descriptive study was approved by the local ethics committee, Comissão de Ética para Análise de Projetos de Pesquisa do HCFMUSP (CapPesq, 0968/2007).

Assessment of physical performance - The Short Physical Performance Battery (SPPB) was used to evaluate the static balance when standing, gait speed at a regular pace, and a movement consisting of sitting down and standing up $^{7)}$. Performance was measured by the time spent during each test, with scores ranging from 0 to 4 . The total score on the SPPB is obtained by adding together the scores of each test; it ranged from 0 (the worst performance) to 12 points (the best performance).

Assessment of mobility - The Timed Up and Go (TUG) test was used to assess functional mobility and dynamic function $^{8)}$. An execution time of 10 seconds is assumed as the standard performance, while a time between 11 and 20 seconds indicates frailness or disability and a time of over 20 seconds indicates an important mobility injury.

Assessment of Balance - The Berg Balance Scale (BERG) was used to evaluate static and dynamic functional balance, with high specificity to predict people with an increased risk of falling by means of a scale of 14 items associated with specific functional tasks ${ }^{9}$. The total score ranges from 0 to 56 points, representing the range of worst to best performance respectively.

Assessment of lower limb muscle strength - Leg press equipment was used to determine the maximum muscle strength using the one-repetition maximum (1-RM) for triple extension of the lower limbs. The test was performed by progressive raising of load, beginning with approximately $50 \%$ of the load that would be used in the first attempt. The participant needed to perform the complete range of extension of the lower limb with no hyperextension of the knee to qualify the attempt. For each load tested, 3 qualified attempts were required to determine the load corresponding to the 1-RM. One or two minutes of resting were allowed between trials ${ }^{10)}$

The Minitab 15.1 software (Minitab, State College, PA, USA) was used to perform statistical analysis. Descriptive analysis was performed to characterize the 3 groups. To determine the differences between groups and gender, twofactor (group and gender) analysis of variance with Tukey's test as a post hoc test or, when appropriate, the KruskalWallis test with Bonferroni correction was used to compare the 6 subgroups comprised of the 3 original age-stratified groups (G1, G2 and G3) divided by gender. Statistical significant was set at $\mathrm{p}<0.05$.

\section{RESULTS}

The clinical and sociodemographic characteristic of the studied population are shown in Table 1. Female participants were predominant in the 3 groups $(\mathrm{G} 1=31$ male, 53 female [58.49\%]; G2=42 male, 65 female [64.61\%]; G3=23 male, 34 female [67.64\%]). The descriptive statistics of the tests are shown in Table 2.

Comparison by gender for the entire population (G1,
Table 1. The sociodemographic and clinical data of the study population $(\mathrm{n}=152)$ by age group

\begin{tabular}{|c|c|c|c|}
\hline \multirow[b]{2}{*}{ Characteristics } & \multicolumn{3}{|c|}{ Groups } \\
\hline & G1 $(n=53)$ & $\mathrm{G} 2(\mathrm{n}=65)$ & $\mathrm{G} 3(\mathrm{n}=34)$ \\
\hline \multicolumn{4}{|l|}{ Gender N (\%) } \\
\hline Female & $31(58.5)$ & $42(64.6)$ & $23(67.6)$ \\
\hline Male & $22(41.5)$ & $23(35.4)$ & $11(32.4)$ \\
\hline \multicolumn{4}{|c|}{ Anthropometric data (mean \pm standard deviation) } \\
\hline Weight (kg) & $71.2 \pm 13.3$ & $68.3 \pm 13.0$ & $60.3 \pm 11.8$ \\
\hline Height (cm) & $161.6 \pm 9.4$ & $156.4 \pm 9.5$ & $153.4 \pm 6.2$ \\
\hline $\operatorname{BMI}\left(\mathrm{kg} / \mathrm{cm}^{2}\right)$ & $27.2 \pm 4.1$ & $27.9 \pm 4.9$ & $25.5 \pm 4.2$ \\
\hline \multicolumn{4}{|l|}{ Marital status (\%) } \\
\hline Single & 11.3 & 7.7 & 14.7 \\
\hline Married & 73.6 & 46.2 & 20.6 \\
\hline Widower & 15.1 & 44.6 & 58.8 \\
\hline Divorced & - & 1.5 & 5.9 \\
\hline \multicolumn{4}{|l|}{ Schooling (\%) } \\
\hline Illiterate & 1.9 & 6.2 & - \\
\hline 1 to 7 years of study & 28.3 & 43.1 & 58.8 \\
\hline 8 years of study & 15.1 & 12.3 & 17.6 \\
\hline $\begin{array}{l}9 \text { to } 10 \text { years of } \\
\text { study }\end{array}$ & 3.8 & - & 5.9 \\
\hline 11 years of study & 18.9 & 10.8 & 2.9 \\
\hline$>11$ years of study & 32.1 & 27.7 & 14.7 \\
\hline \multicolumn{4}{|l|}{ Comorbidities } \\
\hline Number of diseases & $3.1 \pm 1.9$ & $3.7 \pm 2.1$ & $3.5 \pm 2.1$ \\
\hline Number of drugs & $3.4 \pm 2.8$ & $4.9 \pm 4.1$ & $4.9 \pm 2.9$ \\
\hline $\begin{array}{l}\text { Number of hospital } \\
\text { admissions }\end{array}$ & $0.1 \pm 0.3$ & $0.2 \pm 0.5$ & $0.3 \pm 0.8$ \\
\hline \multicolumn{4}{|l|}{ Falls (mean $\pm \mathrm{SD})$} \\
\hline Number of falls & $0.7 \pm 1.1$ & $1.0 \pm 1.2$ & $1.5 \pm 1.7$ \\
\hline
\end{tabular}

G2, and G3) using Kruskal-Wallis test showed differences in SPPB and BERG distributions (SPPB, $\mathrm{p}=0.016$; BERG, $\mathrm{p}=0.030$ ). Pairwise comparisons after Bonferroni correction showed differences between G1 and G3 (SPPB, $\mathrm{p}=0.001$; BERG, $\mathrm{p}=0.009$ ) and $\mathrm{G} 2$ and $\mathrm{G} 3$ (SPPB, $\mathrm{p}=0.001$; BERG, $p=0.009$ ) for women. No differences were found between groups for men.

Analysis of variance of leg press and square root of TUG scores showed the effect of group (TUG, $\mathrm{p}=0.002$; leg press, $\mathrm{p}<0.001$ ) and gender (leg press, $\mathrm{p}<0.001$ ). As no interactions between group by gender (TUG, $\mathrm{p}=0.494$; leg press, $\mathrm{p}=0.556$ ) were found, pairwise comparisons among levels of group were performed and showed that TUG scores decreased in comparisons between G1 and G3 (TUG, $p=0.001$; leg press, $\mathrm{p}<0.001$ ) and between G2 and G3 (TUG, $\mathrm{p}=0.020$; leg press, $\mathrm{p}=0.008$ ).

\section{DISCUSSION}

This study aimed to compare physical performance, balance, mobility, and muscle strength among 152 elderly volunteers from 60 to 96 years old divided in age-stratified groups. We used the SPPB, BERG, TUG test, and leg press 
Table 2. Descriptive statistics of the SPPB, BERG, TUG, and leg press tests

\begin{tabular}{|c|c|c|c|c|}
\hline Test & Group & Gender & $\begin{array}{c}\text { Median } \\
\text { (min-max) }\end{array}$ & Mean (SD) \\
\hline \multirow{6}{*}{ SPPB } & \multirow{2}{*}{$\mathrm{Gl}^{\#}$} & $\mathrm{~F}$ & $11(0-12)$ & \\
\hline & & M & $11.5(6-12)$ & \\
\hline & \multirow{2}{*}{$\mathrm{G} 2^{\#}$} & $\mathrm{~F}$ & $11(10-12)$ & \\
\hline & & M & $12(7-12)$ & \\
\hline & \multirow{2}{*}{$\mathrm{G} 3^{* *}$} & F & $9(6-12)$ & \\
\hline & & M & $12(7-12)$ & \\
\hline \multirow{6}{*}{ BERG } & \multirow{2}{*}{$\mathrm{G}^{\#}$} & $\mathrm{~F}$ & $56(50-56)$ & \\
\hline & & M & $56(30-56)$ & \\
\hline & \multirow{2}{*}{$\mathrm{G} 2^{\#}$} & $\mathrm{~F}$ & $52.5(29-56)$ & \\
\hline & & M & $55(44-56)$ & \\
\hline & \multirow{2}{*}{$\mathrm{G}^{\#}$} & $\mathrm{~F}$ & $47(47-56)$ & \\
\hline & & M & $51(40-56)$ & \\
\hline \multirow{3}{*}{ TUG* } & G1 & & & $9.03(0.31)$ \\
\hline & $\mathrm{G} 2$ & & & $9.94(2.67)$ \\
\hline & G3 & & & 13.67 (6.79) \\
\hline \multirow{3}{*}{ Leg press* } & G1 & & & 74.15 (25.41) \\
\hline & G2 & & & $61.38(24.30)$ \\
\hline & G3 & & & $39.41(21.12)$ \\
\hline
\end{tabular}

test to compare elderly people at their 60 s, 70 s and above 80 s. The assessments were compared by gender for the entire population, and pairwise comparisons were used to show differences between groups.

The results of our study showed that elderly people in their $60 \mathrm{~s}$ and $70 \mathrm{~s}$ had similar functional characteristics (physical performance, balance, mobility, and muscle strength) for both genders and that these characteristics started to decline in the elderly people in their 80s. Elderly women in their 70 s displayed a decline in physical performance and balance. The aging process leads to sarcopenia, with affects about 13 to $24 \%$ of elderly people in their 60 s and $70 \mathrm{~s}$ and more than $50 \%$ of the elderly in their $80 \mathrm{~s}^{11)}$. These alterations of muscle tissues were associated with muscle stiffness, poor muscle recruitment, compromised balance, and compromised functional capacity ${ }^{12,13)}$. The prevalence of falls among elderly people in their $80 \mathrm{~s}$ in Brazil is higher than for elderly people in their $60 \mathrm{~s}$ and $70 \mathrm{~s}$ which may be caused by the decline in functionality ${ }^{14}$. Prevention programs have shown a positive impact on maintenance of functionality, and the practice of getting regular physical activity promotes physical fitness, functional autonomy, and healthy aging ${ }^{15}$ 16). The results of our study highlight the importance of applying specific programs to motivate elderly people in their 70 s and 80 s to become physically active and delay functional losses.

Women in their 70s show a significant decline in functionality (physical performance and balance) compared with men of the same age. Elderly women display greater loss of muscle mass and muscle strength, and these losses predispose women to develop frailty syndrome. Furthermore, there are more elderly women worldwide than men, and the physical disabilities occur frequently in women ${ }^{17)}$. Thus, women have a higher life expectancy than men and are predisposed to losing the protective factor of social support for the prevention of functional and psychological disability.

This study addressed important issues concerning physical decline to alert health professionals about the need for attention in prevention programs for elderly people. The practice of regular physical activity improves the level physical activity and helps elderly people to maintain and/or improve functional capacity, thus enabling healthy aging.

Although important clinical contributions have been mentioned, limitations should also be considered. Agerelated decline is known to be a multidisciplinary issue. It is recommended that further multidisciplinary studies be undertaken to check other components such as psychological issues. We also do not know if the elderly people were physically active. It is unknown if elderly people in their 60s and 70s have similar functional characteristics (physical performance, balance, mobility, and muscle strength for both genders) due to performance of exercises or not. Future studies are needed to verify the influence of physical activities among age-stratified groups of elderly people.

\section{ACKNOWLEDGEMENT}

We acknowledge support from the Department of Physiotherapy, Communication Science and Disorders, Occupational Therapy, Faculty of Medicine, University of São Paulo, Brazil

\section{REFERENCES}

1) Rantanen $T$, Avlund $K$, Suominen $H$, et al.: Muscle strength as a predictor of onset of ADL dependence in people aged 75 years. Aging Clin Exp Res, 2002, 14: 10-15. [Medline]

2) Vasunilashorn S, Coppin AK, Patel KV, et al.: Use of the short physical performance battery score to predict loss of ability to walk 400 meters: analysis from the InCHIANTI study. J Gerontol A Biol Sci Med Sci, 2009, 64: 223-229. [Medline] [CrossRef]

3) Cruz-Jentoft AJ, Baeyens JP, Bauer JM, et al.: Sarcopenia: European consensus on definition and diagnosis: report of the European Working Group on Sarcopenia in older people. Age Ageing, 2010, 39: 412-423. [Medline] [CrossRef]

4) Hurley BF: Age, gender, and muscular strength. J Gerontol A Biol Sci Med Sci, 1995, 50: 41-44. [Medline]

5) Wiacek M, Zubrzycki IZ: The age-dependent divergence of strength and coordinating parameters among men and women: the cross-sectional studies. Arch Gerontol Geriatr, 2010, 51: e75-e78. [Medline] [CrossRef]

6) Bertolucci PH, Brucki SM, Campacci SR, et al.: The Mini-Mental State Examination in a general population: impact of educational status. Arq Neuropsiquiatr, 1994, 52: 1-7. [Medline] [CrossRef]

7) Nakano MM: Brazilian Version of the Short Functional performance Battery - SPPB: cultural adaptation and reliability study. Dissertation, 2007, State University of Campinas (in Portuguese).

8) Freter SH, Fruchter N: Relationship between timed 'up and go' and gait time in an elderly orthopaedic rehabilitation population. Clin Rehabil, 2000, 14: 96-101. [Medline] [CrossRef]

9) Muir SW, Berg K, Chesworth B, et al.: Use of the Berg Balance Scale for predicting multiple falls in community-dwelling elderly people: a prospective study. Phys Ther, 2008, 88: 449-459. [Medline] [CrossRef]

10) Matuszak ME, Fry AC, Weiss LW, et al.: Effect of rest interval length on repeated 1 repetition maximum back squats. J Strength Cond Res, 2003, 17: 634-637. [Medline]

11) Leite LE, Resende TL, Nogueira GM, et al.: Envelhecimento, estresse oxidative e sarcopenia: uma abordagem sistêmica. Rev Bras Geriatr Gerontol, 
2012, 15: 365-380. [CrossRef]

12) Peterson MD, Rhea MR, Sen A, et al.: Resistance exercise for muscular strength in older adults: a meta-analysis. Ageing Res Rev, 2010, 9: 226237. [Medline] [CrossRef]

13) Marsh AP, Rejeski WJ, Espeland MA, et al.: LIFE Study Investigators: Muscle strength and BMI as predictors of major mobility disability in the Lifestyle Interventions and Independence for Elders pilot (LIFE-P). J Gerontol A Biol Sci Med Sci, 2011, 66: 1376-1383. [Medline] [CrossRef]

14) Siqueira FV, Facchini LA, Silveira DS, et al.: Prevalence of falls in elderly in Brazil: a countrywide analysis. Cad Saude Publica, 2011, 27: 1819-1826. [Medline] [CrossRef]
15) Fried LP, Tangen CM, Walston J, et al. Cardiovascular Health Study Collaborative Research Group: Frailty in older adults: evidence for a phenotype. J Gerontol A Biol Sci Med Sci, 2001, 56: M146-M156. [Medline] [CrossRef]

16) Tamai SA, Paschoal SM, Litvoc J, et al.: Impacto de um programa e promoção da saúde na qualidade de vida do idoso. Einstein, 2011, 9: 8-13 (in Portuguese).

17) Ethgen O, Gillain D, Gillet P, et al.: Age- and sex-stratified prevalence of physical disabilities and handicap in the general population. Aging Clin Exp Res, 2004. 16: 389-397. [Medline] [CrossRef] 